\section{A new classification of foods based on the extent and purpose of their processing}

\author{
Uma nova classificação de alimentos baseada na \\ extensão e propósito do seu processamento
}

\author{
1 Faculdade de Saúde \\ Pública, Universidade de São \\ Paulo, São Paulo, Brasil. \\ 2 Faculdade de Medicina, \\ Universidade de São Paulo, \\ São Paulo, Brasil. \\ 3 Núcleo de Pesquisas \\ Epidemiológicas em Nutrição \\ e Saúde, Universidade de São \\ Paulo, São Paulo, Brasil. \\ 4 Instituto de Nutrição, \\ Universidade do Estado do \\ Rio de Janeiro, Rio de Janeiro, \\ Brasil. \\ 5 World Public Health \\ Nutrition Association, Rio de \\ Janeiro, Brasil. \\ Correspondence \\ C. A. Monteiro \\ Departamento de Nutrição. \\ Faculdade de Saúde Pública \\ Universidade de São Paulo. \\ Av. Dr. Arnaldo 715, São Paulo \\ SP 01246-904, Brasil. \\ carlosam@usp.br
}

\begin{abstract}
This paper describes a new food classification which assigns foodstuffs according to the extent and purpose of the industrial processing applied to them. Three main groups are defined: unprocessed or minimally processed foods (group 1), processed culinary and food industry ingredients (group 2), and ultra-processed food products (group 3). The use of this classification is illustrated by applying it to data collected in the Brazilian Household Budget Survey which was conducted in 2002/2003 through a probabilistic sample of 48,470 Brazilian households. The average daily food availability was 1,792 kcal/person being $42.5 \%$ from group 1 (mostly rice and beans and meat and milk), 37.5\% from group 2 (mostly vegetable oils, sugar, and flours), and 20\% from group 3 (mostly breads, biscuits, sweets, soft drinks, and sausages). The share of group 3 foods increased with income, and represented almost one third of all calories in higher income households. The impact of the replacement of group 1 foods and group 2 ingredients by group 3 products on the overall quality of the diet, eating patterns and health is discussed.
\end{abstract}

Food Processing; Nutrition; Feeding Behavior
Carlos Augusto Monteiro 1

Renata Bertazzi Levy 1,2

Rafael Moreira Claro ${ }^{3}$

Inês Rugani Ribeiro de Castro 4

Geoffrey Cannon 5

\section{Introduction}

It is generally acknowledged that increased production and consumption of industrially processed foods and drinks is an important cause of the current pandemics of obesity and related chronic diseases 1,2. However, dietary assessments, and dietary recommendations typically use classifications of food (and of drink, here included as "food") that largely ignore or minimize the significance of industrial food processing. The significance of food processing in itself, is overlooked.

In this way, foods with very different nutritional profiles and impacts on eating patterns and health, such as whole grains, breakfast cereals, flours, breads, cookies, crackers, and cerealbased snacks such as "power bars", are classified within the same food group of grains or cereals and cereal products. The same applies to whole fresh fruits, sugared canned fruits, and reconstituted sugared fruit beverages (classified within fruits) as well as to fresh meat, chicken and fish, and processed products such as burgers, nuggets and fingers (classified within meat or meat and meat products). Such classifications, derived from the "big four" (or "five") groups originally devised early last century, still dominate official and other authoritative information and education programmes, accounts of population dietary patterns, and reports designed to prevent diseases that are influenced by diet 3,4,5,6. 
Because food processing is minimized, unclear or ignored in such classifications, the generally accepted literature includes only fragmentary information about and insight into the relationships between processed foods, and eating patterns, energy and nutrient intake, and health. Some conclusive evidence has emerged on processed meats and certain types of cancer 2 as well as on sugar-sweetened soft drinks, energy intake, and obesity and diabetes $2,7,8,9,10$. Some evidence exists, though it is still incomplete, on "fast" foods and snacks, and obesity 2,11. But the focus so far has been on the effect only of specific types of processed foods, and not on the overall pattern of processed food production and consumption.

In a previous commentary 13 we have pointed out that a classification of foodstuffs into only two categories, unprocessed and processed, is of little use, since nowadays in both higher-income and lower-income countries and contexts practically all food is processed in some way. We also have proposed that the extent and purpose of food processing should be considered crucial determinants of the influence of foods on eating patterns and the overall quality of diets, given their implications for public and personal health and the risk of disease 12 .

In this paper we outline a new food classification which groups foodstuffs according to the extent and purpose of the industrial processing applied to them. The new classification is designed as a tool to describe food systems and dietary patterns, and how these may affect health and the risk of disease. As a first illustration, we have applied the classification to describe the relative contribution of food groups to the overall and income-specific household food availability in Brazil.

\section{Methods}

\section{The new food classification}

Food processing is defined here as all methods and techniques used by the food, drink and associated industries to turn whole fresh foods into food products. The methods used by farmers and producers in cultivating plants and raising animals also affect the nutritional and other qualities of whole foods 13 , but these are not considered here.

The classification used in this paper assigns foodstuffs to three groups according to the extent and purpose of the processing used in their production.

\section{- Group 1: unprocessed and minimally processed foods}

The first group includes unprocessed and minimally processed foods. Minimal processes are mostly physical. These are applied to single basic foods with the purpose of preserving them and making them more available and accessible, and often safer and more palatable.

These processes include cleaning, portioning, removal of inedible fractions, grating, flaking, squeezing, bottling (in itself), drying, chilling, freezing, pasteurization, fermentation, fat reduction, vacuum and gas packing, and simple wrapping. They may be used by the primary producer, packing house, distributor or retailer, as well as by manufacturers, for eventual sale to consumers. Fresh meat and milk, grains, legumes, nuts, fruits and vegetables, and roots and tubers sold as such are usually minimally processed in various ways. Teas, coffee, herb infusions, tap water and bottled spring water also belong to this group.

\section{- Group 2: processed culinary or food industry ingredients}

The second group includes substances extracted and purified from unprocessed or minimally processed foods in order to produce culinary and/or food industry ingredients.

Physical and also chemical processes such as pressure, milling, refining, hydrogenation and hydrolysis, and use of enzymes and additives, are employed. These processes are different from those used to obtain minimally processed foods, in that they radically change the nature of the original foods.

Typically, foodstuffs in group 2 are inedible or unpalatable by themselves, and have higher energy density and lower nutrient density compared with the whole foods from which they were extracted. They are used in homes or restaurants, in the preparation and cooking of dishes made up of fresh or minimally processed foods (group 1), and also in the industrial development of ultraprocessed products (group 3, see below). Group 2 foods include common food industry and culinary ingredients such as starches and flours, oils and fats, salt, and sugar and sweeteners, and, also, industrial ingredients such as high fructose corn syrup, lactose, and milk and soy proteins. In modern food systems, the processing of most group 2 foods is undertaken by agri-businesses for sale as ingredients to food manufacturers and also directly to consumers. 


\section{- Group 3: ultra-processed food products}

The third group involves ultra-processed food products that are ready to eat or ready to heat with little or no preparation. The processed items in group 1 result from slight modifications of one single basic food. The processed items in group 2 result from the extraction of one specific component also of a single basic food. By contrast, food products in group 3 result from the processing of several foodstuffs, including ingredients from group 2 and unprocessed or minimally processed basic foods from group 1.

Processes used in the production of group 3 products include salting, sugaring, baking, frying, deep frying, curing, smoking, pickling, canning, and also frequently the use of preservatives and cosmetic additives, the addition of synthetic vitamins and of minerals, and sophisticated types of packaging.

The industrial processing of group 3 is designed to create durable, accessible, convenient, attractive ready-to-eat or ready-to-heat products. Most of them are often termed "fast" foods or convenience foods. They are formulated to reduce microbial deterioration ("long shelf life"), to be transportable for long distances, and to be extremely palatable ("high organoleptic quality") and often to be habit-forming. Typically they are designed to be consumed anywhere in fast-food establishments, at home in place of prepared dishes and meals, while watching television, at desks or elsewhere at work, in the street, and while driving. Their processing is usually undertaken by food manufacturers, or else by caterers (such as burger outlets) or food retailers (such as bakeries), for sale to consumers.

Group 3 products can be further divided into ready-to-eat snacks or products liable to be consumed as snacks or desserts, and into pre-prepared ready-to-heat products created to replace home-prepared dishes and meals. The snack and dessert sub-group includes products such as breads, cereal bars, biscuits, chips, cakes and pastries, ice cream, and soft drinks in general. The ready-to-heat sub-group includes frozen pasta and pizza dishes, sausages, chicken nuggets, fish sticks, canned or dehydrated soups, and, also, infant formulas created to replace breast milk, and follow-on milks and baby foods formulated for older children. Most items in both sub-groups are sold not just in supermarkets but in many other types of retail outlet, and are also served in or delivered by fast food caterers.

Table 1 summarizes the extent and purpose of the processes that characterize each of the three food groups, with detailed listings of examples.
The classification used here can be applied to data collected by household food acquisition surveys and also by individual food intake surveys. In the first case, as in the application shown in this article, the household acquisition of individual foods is directly classified into one of the three food groups. When household acquisition includes dishes and meals made in traditional restaurants, the classification is performed after the break-down of the recipe according to the individual foods used in its preparation and cooking. The same principles apply to data collected by individual food intake surveys, except for the fact that the breaking down of dishes into individual foods will be more frequent since it will also involve dishes prepared and cooked at home.

\section{The application of the new classification}

\section{- Data source, studied population and sampling}

The data analyzed in this study are derived from the Brazilian Household Budget Survey (HBS) carried out in Brazil by the Brazilian Institute of Geography and Statistics (IBGE) between July 2002 and June 2003.

Sampling of the HBS involved prior definition of socio-geographic strata, integrated by census tracts with similar average socioeconomic indicators. Census tracts were randomly selected from within each stratum, and households were randomly selected from within each tract. In order to make data collection uniform across the year's four trimesters, the interviews carried out within each stratum were spread out across the 12 months of the survey. The total number of households studied was 48,470. A detailed description of the Brazil HBS sampling strategy is available elsewhere 14

The reference period for collecting information on food purchases in each household was seven consecutive days. Since such a short reference period is insufficient for reliable characterization of the food purchase pattern of individual households, we used groups of households belonging to the same sampling strata as our units of analysis $(n=443)$. Therefore, each unit of analysis in our study comprises households that are homogeneous in terms of territorial domain and family income, surveyed uniformly throughout the four trimesters of the year. The mean number of households surveyed in the 443 units was 109.6 (ranging from 9 to 804). The sampling weight of each unit of analysis corresponded to the sum of the sampling weights of the individual households surveyed in the unit. 
Table 1

Food classification based on the extent and purpose of industrial processing.

\begin{tabular}{|c|c|c|}
\hline Food group & Extent and purpose of processing & Examples * \\
\hline $\begin{array}{l}\text { Group 1: unprocessed or } \\
\text { minimally processed foods }\end{array}$ & $\begin{array}{c}\text { No processing, or mostly physical processes used to make } \\
\text { single whole foods more durable, accessible, convenient, } \\
\text { palatable, or safe }\end{array}$ & $\begin{array}{l}\text { Fresh, chilled, frozen, vacuum-packed fruits, vegetables, } \\
\text { fungi, roots and tubers; grains (cereals) in general; fresh, } \\
\text { frozen and dried beans and other pulses (legumes); dried } \\
\text { fruits and } 100 \% \text { unsweetened fruit juices; unsalted nuts } \\
\text { and seeds; fresh, dried, chilled, frozen meats, poultry } \\
\text { and fish; fresh and pasteurized milk, fermented milk such } \\
\text { as plain yoghurt; eggs; teas, coffee, herb infusions, tap } \\
\text { water, bottled spring water }\end{array}$ \\
\hline $\begin{array}{l}\text { Group 2: processed culinary } \\
\text { or food industry ingredients }\end{array}$ & $\begin{array}{l}\text { Extraction and purification of components of single whole } \\
\text { foods, resulting in producing ingredients used in the } \\
\text { preparation and cooking of dishes and meals made up } \\
\text { from Group } 1 \text { foods in homes or traditional restaurants, or } \\
\text { else in the formulation by manufacturers of Group } 3 \text { foods }\end{array}$ & $\begin{array}{l}\text { Vegetable oils, margarine, butter, milk cream lard; sugar, } \\
\text { sweeteners in general; salt; starches, flours, and "raw" } \\
\text { pastas and noodles (made from flour with the addition } \\
\text { only of water); and food industry ingredients usually } \\
\text { not sold to consumers as such, including high fructose } \\
\text { corn syrup, lactose, milk and soy proteins, gums, and } \\
\text { preservatives and cosmetic additives }\end{array}$ \\
\hline $\begin{array}{l}\text { Group 3: ultra-processed } \\
\text { food products }\end{array}$ & $\begin{array}{l}\text { Processing of a mix of Group } 2 \text { ingredients and Group } \\
1 \text { foodstuffs in order to create durable, accessible, } \\
\text { convenient, and palatable ready-to-eat or to-heat food } \\
\text { products liable to be consumed as snacks or desserts or } \\
\text { to replace home-prepared dishes }\end{array}$ & $\begin{array}{l}\text { Breads, biscuits (cookies), cakes and pastries; ice cream; } \\
\text { jams (preserves); fruits canned in syrup; chocolates, } \\
\text { confectionery (candies), cereal bars, breakfast cereals with } \\
\text { added sugar; chips, crisps; sauces; savoury and sweet } \\
\text { snack products; cheeses; sugared fruit and milk drinks and } \\
\text { sugared and "no-cal" cola, and other soft drinks; frozen } \\
\text { pasta and pizza dishes; pre-prepared meat, poultry, fish, } \\
\text { vegetable and other "recipe" dishes; processed meat } \\
\text { including chicken nuggets, hot dogs, sausages, burgers, } \\
\text { fish sticks; canned or dehydrated soups, stews and pot } \\
\text { noodle, salted, pickled, smoked or cured meat and fish; } \\
\text { vegetables bottled or canned in brine, fish canned in oil; } \\
\text { infant formulas, follow-on milks, baby food }\end{array}$ \\
\hline
\end{tabular}

* These listings do not include alcoholic drinks. The examples given are not meant to be complete. Many others can be added, especially to group 3, using the general principles specified in the text and as indicated in the second column.

\section{- Data collection}

The Brazil HBS was designed to obtain reliable information on all sources of household income and all household expenses. Data on income and other socio-demographic variables were obtained by trained field workers using standardized questionnaires. Information on foods and drinks purchased by each household was obtained using the survey's collective expense notebook. In this notebook, one household member was asked to record all food purchases made by the household during seven consecutive days. During this period, the recording task was supervised on a daily basis by the fieldworker responsible for the household. The record of food purchases included the actual quantity of food acquired by the household and the corre- sponding monetary expense. Quantities of specific food items acquired by the households were calculated directly from the expense notebook or, in the case of missing information, derived from average costs estimated from the remaining households in the same sampling stratum.

Individual expenses with food made by members of the household when eating outside the home were also collected by the HBS, but with insufficient detail to allow for estimating the type and quantity of food acquired. Therefore, this study is restricted to foods available for consumption in the household. Expenses on food consumed in households amounted to $75.9 \%$ of total food expenses by all household members in Brazil 15 . 


\section{- Data analysis}

Food purchase records were converted into energy (kcal) using the Brazilian Food Composition Table (TACO, version 1. Núcleo de Estudos e Pesquisas em Alimentação, Universidade Estadual de Campinas, Campinas, Brazil). A few food items were not listed in this table; in such cases the USDA National Nutrient Database for Standard Reference, version 16 was used (Agricultural Research Service, United States Department of Agriculture, Washington DC, USA). Alcoholic drinks were not included in this study. Takeaway dishes prepared in restaurants were also excluded because their description did not allow for the breakdown of recipes according to the individual foods used in their preparation and cooking. Expenses on alcoholic drinks and take-away dishes amounted, as recorded, to less than $4 \%$ of total household food expenses in 2002/2003 (Sistema IBGE de Recuperação Automática. Pesquisa de Orçamentos Familiares, 2002. http://www.sidra.ibge.gov.br/ $\mathrm{bda} /$ pesquisas $/$ pof $/$ default.asp $\mathrm{O}=15 \& \mathrm{i}=\mathrm{P}[3$, accessed on 03/Feb/2010).

After the conversion of purchased items into energy, the average daily per capita energy availability (and corresponding standard error) provided by the food purchases as recorded, was estimated. The same estimate was calculated according to ascending quintiles of the average household income distribution for all Brazilian households in 2002/2003.

In the next step, individual food purchases to the food groups displayed in Table 2 were assigned. Then estimates and standard errors for the relative contribution as a percentage of each food group to the total energy available for household consumption were calculated. The same estimates were also calculated according to the quintiles of the household income distribution.

The association between household income and the participation of each food group in total food purchases was tested by linear regression of the five income quintiles on the percentage of calories provided by each food group. Weighting factors were used to allow for the extrapolation of the results to all Brazilian households in 2002/2003. All analyses were carried out using Stata version 9.2 (Stata Corp., College Station, USA) and accounted for the effect of weights on the standard errors of the estimates.

\section{Results}

The sum of all household food purchases made by Brazilian households corresponded to an average daily availability of $1,792 \mathrm{kcal}$ per person. A little more than $40 \%$ of these calories came from the group of unprocessed or minimally processed foods (group 1), mostly from rice and beans, meat and milk. Another $38 \%$ of all purchased calories came from the group of processed culinary ingredients (group 2), mostly from vegetable oils, sugar, and manioc and wheat flours. The remaining $20 \%$ of calories came from ultra-processed food products (group 3), mostly from breads, biscuits, sweets (candies), soft drinks, and processed meats (Table 2).

The average daily per capita energy availability in each ascending quintile of the household income distribution (with corresponding standard errors in parenthesis) was $1,914 \mathrm{kcal}$ (60), 1,885 (101), 1,824 (85), 1,673 (95), and 1,639 (38), respectively.

Table 3 shows the caloric share attributed to specific food groups in each quintile of household income distribution. The share of ultra-processed food products increased significantly with income: from $12.6 \%$ of total calories in the lowest income group to over double this figure, $30.2 \%$, in the highest income group. Except for biscuits and processed meats other than sausages, all the remaining group 3 items were consumed more as income rose. For instance, breads represented $4.4 \%$ of total calories in the lowest income group and $11.2 \%$ in the highest income group. Altogether, sweets (candies), soft drinks, sausages, and cheeses amounted to $2 \%$ of total calories for the poorest households and $10.2 \%$ for the richest households.

In general, the caloric share of unprocessed or minimally processed foods (group 1) and processed culinary ingredients (group 2) decreased as household income increased. The gap between the lowest and the highest income groups was $6 \%$ for group 1 and $12 \%$ for group 2 foods. Group 1 lost importance as income rose, mostly as a result of a decrease in the quantities of rice and beans purchased. With group 2 the drop in purchases by the higher income groups included manioc flour, sugar and corn flour. Purchase and consumption of some foods in group 1, such as milk, fruits, and vegetables, and in group 2 , such as wheat flour and vegetables oils, tended to rise with increases in income. 
Household availability of food groups classified according to the extent and purpose of industrial processing. Brazil, 2002/2003.

\begin{tabular}{|c|c|c|}
\hline Food groups/Foods & $\begin{array}{c}\text { kcal/day/person } \\
\text { Mean (SE) }\end{array}$ & $\begin{array}{c}\text { Total calories (\%) } \\
\text { Mean (SE) }\end{array}$ \\
\hline Group 1: unprocessed or minimally processed foods & $767.9(20.7)$ & $42.5(0.4)$ \\
\hline Rice & $301.4(12.6)$ & $16.6(0.5)$ \\
\hline Meats (not fish) & $141.8(3.0)$ & $8.2(0.2)$ \\
\hline Beans & $116.3(5.7)$ & $6.3(0.2)$ \\
\hline Milk & $86.6(2.6)$ & $4.9(0.1)$ \\
\hline Fruits & $32.7(1.1)$ & $1.9(0.1)$ \\
\hline Roots and tubers & $19.9(1.3)$ & $1.1(0.1)$ \\
\hline Vegetables & $12.4(0.4)$ & $0.7(0.0)$ \\
\hline Fish & $9.4(1.3)$ & $0.5(0.1)$ \\
\hline Eggs & $6.0(0.9)$ & $0.3(0.0)$ \\
\hline Other * & $41.6(5.1)$ & $2.0(0.2)$ \\
\hline Group 2: processed ingredients & $685.0(19.5)$ & $37.5(0.6)$ \\
\hline Sugar (sucrose) & $223.9(8.0)$ & $12.4(0.3)$ \\
\hline Vegetable oils & $203.6(7.7)$ & $11.3(0.3)$ \\
\hline Manioc flour & $76.3(10.2)$ & $4.0(0.5)$ \\
\hline Wheat flour & $49.1(5.6)$ & $2.5(0.3)$ \\
\hline Pasta & $40.7(1.1)$ & $2.3(0.1)$ \\
\hline Vegetable fats (margarines, coconut fat) & $27.3(0.9)$ & $1.6(0.1)$ \\
\hline Animal fats (butter, lard, and cream) & $17.0(1.7)$ & $0.9(0.1)$ \\
\hline Other $\star \star$ & $47.1(3.8)$ & $2.5(0.2)$ \\
\hline Group 3: ultra-processed food products & $338.6(9.4)$ & $20.0(0.6)$ \\
\hline Breads & $127.6(4.2)$ & $7.8(0.3)$ \\
\hline Biscuits & $56.3(1.7)$ & $3.3(0.1)$ \\
\hline Sweets & $28.6(1.9)$ & $1.7(0.1)$ \\
\hline Soft drinks & $27.7(1.6)$ & $1.6(0.1)$ \\
\hline Sausages & $27.1(1.5)$ & $1.6(0.1)$ \\
\hline Cheeses & $16.6(1.1)$ & $0.9(0.1)$ \\
\hline Salted/Cured/Smoked meats & $15.2(1.0)$ & $0.8(0.0)$ \\
\hline Canned, frozen or dehydrated dishes & $9.9(0.7)$ & $0.6(0.0)$ \\
\hline Sauces including mayonnaise & $6.2(0.4)$ & $0.4(0.0)$ \\
\hline Other $* \star \star$ & $23.4(1.1)$ & $1.4(0.1)$ \\
\hline All foods & $1,791.5(36.0)$ & 100.0 \\
\hline
\end{tabular}

SE: standard errors.

* Grains (other than rice and beans), nuts and seeds (unsalted), shellfish, coffee, tea, and dried condiments;

** Corn flour, starches, others sugars and sweeteners, and coconut milk;

*** Salted and dried or oil-preserved canned fishes, canned vegetables in brine, instant noodles, sugared breakfast cereals, sugared milk beverages, and other sugared beverages.

\section{Discussion}

Proper understanding of the impact of food systems and dietary patterns on health and the risk of disease depends on the conceptual framework used for classifying foods.

Study designs, results and conclusions in this field, and therefore also public policy recommen- dations, are driven by the way foods are classified. Studies and reports on food, nutrition and health continue to assume that the appropriate classifications of foods are based on a mixture of their nutrient profile (such as the amount of saturated fats or zinc they contain), and their original nature (such as meat or fruits). This paper proposes that such classifications are relevant, but not the 
Relative contribution (\%) of food groups classified according to the extent and purpose of industrial processing to total energy availability by household income. Brazil, 2002/2003.

\begin{tabular}{|c|c|c|c|c|c|c|}
\hline \multirow[t]{3}{*}{ Food groups/foods } & \multirow{2}{*}{\multicolumn{5}{|c|}{$\begin{array}{l}\text { Fifths of the household income distribution } \\
\qquad \% \text { (SE) }\end{array}$}} & \multirow{3}{*}{$\begin{array}{l}\mathrm{p} \text {-value for } \\
\text { linear trend }\end{array}$} \\
\hline & & & & & & \\
\hline & 1 th & 2nd & $3 r d$ & 4th & 5 th & \\
\hline Group 1: unprocessed or minimally processed foods & $44.5(1.4)$ & $44.6(1.0)$ & $43.0(0.7)$ & $41.4(0.6)$ & $38.5(0.6)$ & $<0.001$ \\
\hline Rice & $17.4(1.5)$ & $18.7(1.0)$ & $17.9(0.9)$ & $15.9(1.0)$ & $12.7(0.7)$ & 0.001 \\
\hline Meats (not fish) & $7.1(0.3)$ & $8.5(0.4)$ & $8.3(0.6)$ & $9.3(0.4)$ & $8.0(0.2)$ & 0.009 \\
\hline Beans & $9.4(0.5)$ & $6.9(0.3)$ & $6.0(0.2)$ & $4.9(0.3)$ & $4.1(0.2)$ & $<0.001$ \\
\hline Milk & $3.5(0.1)$ & $4.3(0.2)$ & $4.9(0.2)$ & $5.3(0.2)$ & $6.5(0.2)$ & $<0.001$ \\
\hline Fruits & $1.3(0.1)$ & $1.5(0.1)$ & $1.6(0.1)$ & $2.1(0.1)$ & $3.1(0.1)$ & $<0.001$ \\
\hline Roots and tubers & $0.9(0.1)$ & $1.0(0.1)$ & $1.0(0.1)$ & $1.2(0.1)$ & $1.3(0.1)$ & 0.001 \\
\hline Vegetables & $0.5(0.0)$ & $0.6(0.0)$ & $0.6(0.0)$ & $0.8(0.0)$ & $1.0(0.0)$ & $<0.001$ \\
\hline Fish & $0.9(0.2)$ & $0.8(0.2)$ & $0.3(0.1)$ & $0.2(0.0)$ & $0.3(0.0)$ & $<0.001$ \\
\hline Eggs & $0.3(0.0)$ & $0.4(0.1)$ & $0.3(0.1)$ & $0.3(0.2)$ & $0.3(0.1)$ & 0.810 \\
\hline Other * & $3.3(0.5)$ & $1.9(0.4)$ & $2.2(0.5)$ & $1.3(0.3)$ & $1.2(0.1)$ & $<0.001$ \\
\hline Group 2: processed ingredients & $42.8(1.2)$ & $39.7(0.9)$ & $38.5(0.9)$ & $34.3(1.3)$ & $31.3(0.8)$ & $<0.001$ \\
\hline Sugar (sucrose) & $13.2(0.3)$ & $13.4(0.5)$ & $13.7(0.7)$ & $11.0(0.4)$ & $10.0(0.4)$ & $<0.001$ \\
\hline Vegetable oils & $9.1(0.3)$ & $11.2(0.7)$ & $12.3(0.5)$ & $12.6(0.9)$ & $11.6(0.5)$ & $<0.001$ \\
\hline Manioc flour & $10.9(1.2)$ & $5.4(1.0)$ & $1.8(0.5)$ & $1.0(0.2)$ & $0.8(0.1)$ & $<0.001$ \\
\hline Wheat flour & $0.9(0.1)$ & $2.2(0.4)$ & $3.6(0.5)$ & $3.5(1.0)$ & $2.2(0.4)$ & 0.003 \\
\hline Pasta & $2.2(0.2)$ & $2.4(0.1)$ & $2.4(0.1)$ & $2.3(0.1)$ & $2.3(0.1)$ & 0.973 \\
\hline Vegetable fats (margarines, coconut fat) & $1.2(0.1)$ & $1.6(0.2)$ & $1.5(0.1)$ & $1.7(0.1)$ & $2.1(0.1)$ & $<0.001$ \\
\hline Animal fats (butter, lard, and cream) & $0.4(0.0)$ & $0.9(0.2)$ & $1.1(0.2)$ & $1.0(0.2)$ & $1.0(0.1)$ & $<0.001$ \\
\hline Other $* \star$ & $5.0(0.5)$ & $2.6(0.2)$ & $2.0(0.2)$ & $1.3(0.2)$ & $1.2(0.1)$ & $<0.001$ \\
\hline Group 3: ultra-processed food products & $12.6(0.8)$ & $15.7(1.0)$ & $18.5(0.9)$ & $24.3(1.1)$ & $30.2(0.8)$ & $<0.001$ \\
\hline Breads & $4.4(0.5)$ & $6.9(0.7)$ & $7.4(0.7)$ & $9.6(0.8)$ & $11.2(0.3)$ & $<0.001$ \\
\hline Biscuits & $3.5(0.2)$ & $2.9(0.2)$ & $2.9(0.2)$ & $3.1(0.2)$ & $3.8(0.2)$ & 0.225 \\
\hline Sweets & $0.4(0.0)$ & $0.8(0.1)$ & $1.5(0.1)$ & $2.3(0.2)$ & $3.2(0.2)$ & $<0.001$ \\
\hline Soft drinks & $0.6(0.1)$ & $1.1(0.1)$ & $1.5(0.1)$ & $2.4(0.2)$ & $2.7(0.1)$ & $<0.001$ \\
\hline Sausages & $0.7(0.1)$ & $1.1(0.1)$ & $1.7(0.1)$ & $2.5(0.2)$ & $2.1(0.1)$ & $<0.001$ \\
\hline Cheeses & $0.3(0.0)$ & $0.5(0.1)$ & $0.7(0.1)$ & $1.1(0.1)$ & $2.2(0.2)$ & $<0.001$ \\
\hline Salted/Cured/Smoked meats & $1.0(0.1)$ & $0.8(0.1)$ & $0.8(0.1)$ & $0.7(0.1)$ & $0.8(0.1)$ & 0.096 \\
\hline Canned, frozen or dehydrated dishes & $0.1(0.0)$ & $0.3(0.0)$ & $0.4(0.1)$ & $0.7(0.0)$ & $1.5(0.1)$ & $<0.001$ \\
\hline Sauces including mayonnaise & $0.1(0.0)$ & $0.2(0.0)$ & $0.4(0.0)$ & $0.5(0.0)$ & $0.7(0.0)$ & $<0.001$ \\
\hline 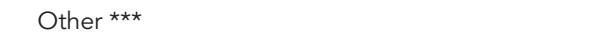 & $1.4(0.1)$ & $1.0(0.1)$ & $1.1(0.1)$ & $1.3(0.1)$ & $2.0(0.1)$ & $<0.001$ \\
\hline All foods & 100.0 & 100.0 & 100.0 & 100.0 & 100.0 & \\
\hline
\end{tabular}

SE: standard error

* Grains (other than rice and beans), nuts and seeds (unsalted), shellfish, coffee, tea, and dried condiments;

** Corn flour, starches, others sugars and sweeteners, and coconut milk;

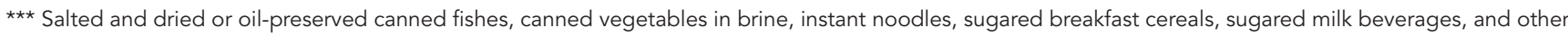
sugared beverages.

most relevant. The issue is not so much nutrients, or foods, as what is done to foods before they are consumed. We propose that the system of food classification that is currently favoured, which pays little attention to food processing, needs to be replaced by a system as outlined here, which concentrates on the extent and purpose of food processing.
This paper is not suggesting that healthy diets are composed only of unprocessed and minimally processed foods and processed ingredients. The issue is one of proportion.

One response may be that in the modern industrialized and urbanized world, food supplies and dietary patterns mostly composed of "fast", "convenience" ready-to-eat and ready-to-heat 
products are desirable or inevitable. While such a point is beyond the scope of this paper, we do not agree. In any case, our immediate concern here is with prevention of diseases, the risks of which are known or reliably believed to be modified by diet, food and nutrition.

The classification used here implies a review of thinking about a number of dietary items. Two obvious examples are sugar and bread. First, sugar. Our view is that "table" sugar, the ingredient, is less of an issue than sugars and syrups added to ready-to-consume processed products, one example being soft drinks. The fact that any type of sugar is chemically identical is not the point. It is above all processing that leads to over-consumption of sugars and syrups. Secondly, bread: all types of bread are often identified as healthy, or else a distinction is made between wholegrain breads, and breads made from refined "white" flour. Our view is that the classification of bread (usually meaning wheat bread) as a group 3 product, is conceptually and factually correct. Also, as consumed, bread, which is itself fairly energydense, is often a vehicle for table fats and other energy-dense products, frequently in the form of sandwiches.

The use of a food classification based on the extent and purpose of food processing shows that processed ready-to-eat or to-heat food products (group 3) represented one fifth of all calories purchased for consumption in Brazilian households in 2002/2003. It also shows that the importance of this group of products increased as income rose, and represented almost one third of all calories in the highest income households. Both unprocessed or minimally processed foods (group 1) and processed ingredients (group 2) lost importance as income rose.

Analysis of retail sales of selected food products in several countries is consistent with the relationship we have observed between income and consumption of different groups of processed foods. This analysis, made by the market research organization Euromonitor, shows that as national income increases, the share of retail sales of ultra-processed food products, such as ready meals and breakfast cereals, correspondingly increases, while the share of minimally processed foods, such as dried foods (mostly grains), and processed culinary ingredients, such as oils and fats, declines 16 .

Time trend data in Brazil are available for the country's 11 metropolitan areas where, according to the Demographic Census of 2000 (IBGE. http://www.ibge.gov.br), one third of the total Brazilian population is concentrated. Analyses of four surveys conducted in these areas in $1974 / 1975,1987 / 1988,1995 / 1996$, and 2002/2003 indicated continuous increases in the caloric share of several group 3 products. Thus across the whole period, sausages and biscuits increased their caloric share by $200 \%$, and soft drinks by $400 \%$. By contrast, rice and beans, traditional staple group 1 foods, declined from $19.1 \%$ to $14.7 \%$ and from $8.1 \%$ to $5.7 \%$, respectively. Other group 1 foods such as meat and milk and fruit and vegetables contributed more calories up to 1995/1996, but showed declines in 2002/2003. The caloric share of processed ingredients (group 2 foods) either remained relatively stable (oils and fats) or decreased (table sugar and manioc flour) 17.

The trends on food purchases seen in metropolitan areas of Brazil up to 2002/2003 indicate that an important feature of the recent shifts in food supplies and dietary patterns in Brazil has been the replacement of unprocessed or minimally processed foods and processed culinary ingredients by ready-to-eat and ready-to-heat products. These trends are likely to have continued, given the reactivation of the country's economy and the continuous increases in family income after 2003 18. This hypothesis will be testable when data from the new national household budget survey, conducted in Brazil in 2008/2009, become available.

\section{Comparisons}

A direct comparison of our results with results obtained in other countries is not yet possible, because we have used a new system of food classification. But a comparison of some specific group 3 foods in countries whose food systems and supplies are more industrialized is enlightening. Thus, using data from a report on a national household food budget survey in the United Kingdom in 200819 and picking up only some products in group 3 of our classification (breads, cakes, buns and pastries, confectionery, biscuits, processed meats, cheeses and soft drinks) we found that at least $45,3 \%$ of total calories came from ready-to-eat or ready-to-heat products, a value twice as high as the $19.1 \%$ for the same products in 2002/2003 in Brazil. This predominance of group 3 products in the UK diet, not yet identified in Brazil, is even more clear in the USA, where the five most commonly consumed foods are all ultra-processed food products: regular soft drinks, cakes and pastries, burgers, pizza, and potato chips. Together these products provided one-fifth (19.8\%) of the total caloric intake in the USA in 1999/2000 20. More recent studies are likely to show a higher percentage.

The positive association of ready-to-eat and ready-to-heat food products (group 3) with income shown in this study, plus the much higher 
caloric share of these products seen in high income countries, suggest that their production and consumption will continue to grow in Brazil and also in other lower-income countries.

\section{Implications}

What are the health implications of the increase in group 3 food products? As yet we cannot know, simply because the classification used here is new. However, many products in group 3, such as soft drinks, biscuits (cookies), ice creams, pastries, processed meats, cheeses, and sauces, are already identified as increasing the risk of obesity and other nutrition-related chronic diseases. In terms of nutrient profile, such products are typically energy-dense, and contain a lot of added sugar, sodium, saturated fats or trans fats and little dietary fiber 21 .

Diets based on group 1 foods and group 2 ingredients are notably different from diets based on group 3 products, in that the latter are more energy-dense. For instance, a popular meal served in fast-food chains operating in Brazil, consisting of bread, burger, French fries and mayonnaise, followed by ice cream, has an energy density of around $3 \mathrm{kcal} / \mathrm{g}$, whereas the traditional Brazilian meal made up of rice, beans and beef, with vegetables and some salad plus oils and seasonings, followed by a fresh fruit, has an energy density of around $1 \mathrm{kcal} / \mathrm{g}$ (calculations based on average serving sizes for Brazil) 22. Even when made with "premium" products (such as whole wheat bread, "low-fat" burger, trans-fat free French fries, "lowfat" mayonnaise and "light" ice cream) the group 3-based meal is still twice as energy-dense as the traditional meal.

Sugared soft drinks are a special case. Evidence of their harmful effects to health is now disputed only by industry representatives and apologists. To date, six systematic reviews have found associations identified as causal between what have now in many countries become typical levels of soft drink consumption and increased calorie intake, overweight and obesity, and serious diseases of which overweight and obesity are a cause 2,7,8,9,10.

Features of group 3 products other than their nutrient composition and energy density, which are not detected by nutrient profiling systems, also make them harmful to health. Such products are relatively unperishable or even imper- ishable (unlike vegetables and fruits), and do not require preparation or cooking (as grains and fresh or frozen meat do). This is why they are usually termed "convenience foods" or "fast foods". But convenience and rapidity in themselves promote patterns of consumption known to harm the mechanisms that regulate energy balance, and therefore increase the likelihood of excess eating and obesity. Such unhealthy eating patterns include snacking instead of regular meals, eating while watching TV, and consuming a lot of energy in liquid form. These are all amplified by intensive and sophisticated marketing techniques targeted particularly at children and adolescents 12,23.

Further, the incredibly low cost of main ingredients such as vegetable oils and fats, starches, sugars and salt used in the production of group 3 products, which are often made even lower by government subsidies, and the limitless opportunities to invent "new" products and market them globally, explain why food industry marketing investments are concentrated on economically "value-added" products, notably soft drinks, burgers, and snacks, and not on minimally processed foods, or even on fats, oils, sugars and syrups used as ingredients 12,23.

As well as current human health, the negative social, economic and environmental impacts of increased production and consumption of group 3 foods needs to be taken into account. As the intensity of food processing increases, typically so does the requirement for energy inputs, directly in the processing itself, and indirectly in packaging and transportation $24,25,26$. Increased production and consumption of group 3 products also results in the weakening of traditional food cultures and the loss of culinary diversity, among very many other adverse effects 27 .

Although more work is needed to understand the impact of ultra-processed food products (group 3) on human health and disease, and on societies, economies, the environment, and the biosphere, the evidence that is already available is in our view an adequate basis for public health action. Those actors responsible for food and nutrition policies 2 need to use all possible methods, including legislation and statutory regulation, to halt and reverse the replacement of minimally processed foods (group 1) and processed culinary ingredients (group 2) by group 3 food products. 


\section{Resumo}

Este artigo descreve uma nova classificação de alimentos baseada na extensão e propósito do processamento industrial usado na sua produção. Três grupos são definidos: alimentos não processados ou minimamente processados (grupo 1), alimentos processados utilizados como ingredientes de preparações culinárias ou pela indústria de alimentos (grupo 2), e produtos alimentícios ultra-processados (grupo 3). O uso da classificação é ilustrado aplicando-a a dados coletados por Pesquisa de Orçamentos Familiares conduzida em 2002/2003 em uma amostra probabilística de 48.470 domicílios brasileiros. A disponibilidade diária foi de $1.792 \mathrm{kcal} / \mathrm{capita}$, sendo $42,5 \%$ de alimentos do grupo $1,37,5 \%$ do grupo 2 e $20 \%$ do grupo 3 . A contribuição do grupo 3 aumentou com a renda familiar, correspondendo a um terço do total calórico nos domicílios mais afluentes. Discute-se o impacto sobre a qualidade geral da dieta, padrões de alimentação e condições de saúde que poderia ocorrer com a substituição de alimentos do grupo 1 e ingredientes do grupo 2 por produtos alimentícios do grupo 3.

Processamento de Alimentos; Nutrição; Comportamento Alimentar

\section{Contributors}

The initial draft of this paper was prepared by C. A. Monteiro following extensive discussions with R. B. Levy, R. M. Claro, I. R. R. Castro, and G. Cannon. Successive drafts were developed by C. A. Monteiro and G. Cannon, with inputs from the other co-authors. The application study was supervised by C. A. Monteiro and undertaken by R. B. Levy and R. M. Claro.

\section{References}

1. World Health Organization. Report of a Joint WHO/FAO Expert Consultation. Diet, nutrition and the prevention of chronic diseases. Geneva: World Health Organization; 2003. (Technical Report Series, 916).

2. World Cancer Research Fund/American Institute for Cancer Research. Food, nutrition, physical activity, and the prevention of cancer: a global perspective. Washington DC: American Institute for Cancer Research; 2007.

3. Painter J, Rah J, Lee Y. Comparison of international food guide pictorial representations. J Am Diet Assoc 2002; 102:483-9.

4. Rodrigues SSP, Almeida MDV. Portuguese household food availability in 1990 and 1995. Public Health Nutr 2001; 4(5B):1167-71.
5. Becker W. Comparability of household and individual food consumption data: evidence from Sweden. Public Health Nutr 2001; 4(5B):1177-82.

6. Demory-Luce D, Morales M, Nicklas T, Baranowski T, Zakeri I, Berenson G. Changes in food group consumption patterns from childhood to young adulthood: The Bogalusa Heart Study. J Am Diet Assoc 2004; 104:1684-91.

7. Bachman CM, Baranowski T, Nicklas TA. Is there an association between sweetened beverages and adiposity? Nutr Rev 2006; 64:153-74.

8. Pereira MA. The possible role of sugar-sweetened beverages in obesity etiology: a review of the evidence. Int J Obesity 2006; 30 Suppl 3:S28-36. 
9. Malik VS, Schulze MB, Hu FB. Intake of sugarsweetened beverages and weight gain: a systematic review. Am J Clin Nutr 2006; 84:274-88.

10. Vartanian LR, Schwartz, B, Brownell KD. Effects of soft drink consumption on nutrition and health: a systematic review and meta-analysis. Am J Public Health 2007; 97:667-75.

11. Rosenheck R. Fast food consumption and increased caloric intake: a systematic review of a trajectory towards weight gain and obesity risk. Obes Rev 2008; 9:535-47.

12. Monteiro CA. Nutrition and health. The issue is not food, nor nutrients, so much as processing. Public Health Nutr 2009; 12:729-31.

13. Hawkes C. Promoting health diets and tackling obesity and diet-related chronic diseases: what are the agricultural policy levers? Food Nutr Bull 2007; 28(2 Suppl):S312-22.

14. Instituto Brasileiro de Geografia e Estatística. Pesquisa de Orçamentos Familiares 2002-2003: análise da disponibilidade domiciliar de alimentos e do estado nutricional no Brasil. Rio de Janeiro: Instituto Brasileiro de Geografia e Estatística; 2004.

15. Instituto Brasileiro de Geografia e Estatística. Pesquisa de Orçamentos Familiares 2002-2003: primeiros resultados, Brasil e Grandes Regiões. Rio de Janeiro: Instituto Brasileiro de Geografia e Estatística; 2004.

16. Gehlhar M, Regmi A. Factors shaping global food markets. In: Regmi A, Gehlhar M, editors. New directions in global food markets. Washington DC: United States Department of Agriculture; 2005. (Agriculture Information Bulletin, 794).

17. Levy-Costa RB, Sichieri R, Pontes NS, Monteiro CA. Disponibilidade domiciliar de alimentos no Brasil: distribuição e evolução (1974-2003). Rev Saúde Pública 2005; 39:530-40.
18. Neri MC, coordenador. Miséria, desigualdade e políticas de renda: o Real do Lula. Rio de Janeiro: Centro de Políticas Sociais, Instituto Brasileiro de Economia, Fundação Getúlio Vargas; 2007.

19. Department for Environment Food and Affairs. UK trends in energy and nutrient. https://statistics. defra.gov.uk/esg/publications/efs/2008/chapter2. pdf (accessed on 03/Feb/2010).

20. Block G. Foods contributing to energy intake in the US: data from NHANES III and NHANES 19992000. J Food Compost Anal 2004; 17:439-47.

21. Astrup A, Dyerberg J, Selleck M, Stender S. Nutrition transition and its relationship to the development of obesity and related chronic diseases. Obes Rev 2008; 9 Suppl 1:48-52.

22. Coordenação Geral da Política de Alimentação e Nutrição, Departamento de Atenção Básica, Secretaria de Atenção à Saúde, Ministério da Saúde. Guia alimentar para a população brasileira: promovendo a alimentação saudável. Brasília: Ministério da Saúde; 2004.

23. Monteiro CA. All the harmful effects of ultra-processed foods are not captured by nutrient profiling. Public Health Nutr 2009; 12:1968.

24. Beauman C, Cannon G, Elmadfa I, Glasauer P, Hoffmann I, Keller M, et al. The Giessen Declaration. Public Health Nutr 2005; 8(6A):783-6.

25. Lawrence M. Food guides: a compromise solution. Public Health Nutr 2009; 12:1305.

26. Roberts P. The end of food. New York: Houghton Mifflin Company; 2008.

27. Contreras Hernández J, Gracia Arnáiz M. Alimentación y cultura: perspectivas antropológicas. Barcelona: Editora Ariel; 2005.

Submitted on $24 / \mathrm{Feb} / 2010$

Final version resubmitted on $07 / \mathrm{Jun} / 2010$

Approved on 15/Jun/2010 